\title{
Assessing E-Service Quality of B2C Sites: A Proposed Framework
}

\author{
Shakeel Iqbal \\ Department of Business Administration, Iqra University, Islamabad, Campus Plot No. 5, Sector \\ H-9, Islamabad, Pakistan \\ Zeeshan Ahmed Bhatti \\ Department of Management Information Systems, Faculty of Economics and Administration, \\ King Abdul Aziz University, Jeddah, Saudi Arabia \\ Muhammad Naeem Khan \\ Department of Business Administration, Iqra University, Islamabad, Campus Plot No. 5, Sector \\ H-9, Islamabad, Pakistan
}

\begin{abstract}
E-services play a crucial role in attracting new online customers as well as retaining the old ones. This research paper is an attempt to define a framework for assessing the quality of e-services offered by B2C e-commerce websites. The proposed e-service quality framework (e-SQF) is applied on ten most popular B2C e-commerce sites of Pakistan to assess their relative state of eservice quality. The selected websites are assessed on each of the eight e-service quality dimensions defined in the e-SQF (i.e., e-search, e-response, e-transaction, e-payment, assurance \& trust, e-help \& e-technologies, post-sales support and website design and functionality). An overall assessment of each of the selected websites is also made to rank them in order of quality of e-services offered. The proposed framework can be a useful tool to quantify the quality of eservices offered by the e-tailers.
\end{abstract}

Keywords: e-service quality, E-tailing, B2C e-commerce, e-service quality framework, eservice quality dimensions

\section{Introduction}

The term e-commerce has been defined differently by different researchers - some have defined e-commerce in a narrower sense as to be any buying and/or selling activity over the internet (e.g., [1]; whereas some others have looked it from a broader perspective covering all online activities [2] including searching, enquiring, ordering, payment order tracking, and post-sales support. "Electronic commerce is not solely restricted to the actual buying and selling of products, but also includes pre-sale and post-sale activities across the supply chain.'[3] p.13. E-commerce activities gained tremendous boost in recent years. According to the Global B2C E-commerce Report 
(2016), 1.4 billion people out of the estimated global population of 7.3 billion purchased goods and/or services online at least once in 2015 [4]. The report further states that worldwide ecommerce spending in 2015 was estimated around US \$2,272.7 billion which means approximately US $\$ 1,582$ were spent by each e-shopper. The top ten countries in terms of ecommerce sales mentioned in the same report during the period 2012-2016 (in descending order) were: China, USA UK, Japan, France, Germany, South Korea, Canada, India and Russia. The trend of online shopping is getting popular in developing countries as well mainly due to the introduction of third generation $(3 \mathrm{G})$ and long-term evolution (LTE) services, reduction in the prices of Smartphones, and growth of online social networks [5]. Pakistan is among those countries which experienced an exponential growth in e-commerce activities and the experts predict that ecommerce industry will cross US\$1 billion benchmark by 2020 [6]. Although e-commerce is gaining widespread popularity in developing countries (including Pakistan); there are several technological, organizational, and regulatory challenges that are limiting the pace and growth of this industry in Pakistan [7]. The United Nations Conference on Trade \& Development (UNCTAD) B2C E-commerce Index 2016 ranked 137 economies of the world on the basis of four indicators - credit card penetration, postal reliability score, internet use penetration and secured internet servers [8]. Pakistan is placed at 105 in this ranking mainly due to the non-availability of data on credit card ownership.

E-commerce is different from face-to-face buying in the sense that there is no one physically present to address the customers concerns and queries. The only means of interaction between the buyer and seller is the seller's website, therefore it can be contended that superior online service quality (referred to as e-SQ in this study) can be crucial differentiating strategy in e-commerce [9]. e-SQ is defined as "the extent to which a website facilitates efficient and effective shopping, purchasing, and delivery" [9] p.17. It can be deduced from this definition that "e-SQ extends from the pre-purchase phase (ease of use, product information, ordering information, and personal information protection) to the post-purchase phase (delivery, customer support, fulfillment, and return policy)" [10] p.1.

[11] and [12] have pointed out that the service quality is the most important factor contributing towards sustained success of the e-tailers. However, the conceptualization and measurement of the concept of e-SQ is yet to mature as pointed out by [13]. Moreover, [14] have highlighted that studies addressing the issue of e-SQ are limited and disparate. Literature review of studies conducted on e-commerce in Pakistan indicates a dearth of studies evaluating the state of e-services offered by Pakistani e-tailers. This study is conducted to fill this gap. The main objectives of this study are:

1. To develop a framework for assessing the quality of e-services offered by B2C websites (e-SQF) in Pakistan

2. To assess the e-SQ of the selected websites of Pakistan on the basis of proposed e-SQF

3. To rank the selected websites on the basis of e-SQ scores awarded using e-SQF 
The remaining part of this research paper is organized as follows: review of relevant literature is presented in the next section, followed by research methodology, results and discussions, and conclusion. Finally, limitations and future directions for research are discussed.

\section{Literature Review}

One of the widely used instruments to measure the service quality of service providers is SERVQUAL [15]. However, it is designed to measure service quality in personal (or physical) interaction among customers and service providers. It is due to the same reason that different researchers have indicated it to be less suitable for measuring service quality in the online context [16] and [9]. Defining service quality in online context is a daunting task as [17] p.467 points out: "construct measurement in the context of web technologies and applications is a challenging task."

There are many studies that are conducted with an objective of evaluating the websites - each evaluating the websites with a distinct set of matrices. For example, [18] proposed a website evaluation index based on the objectivity, usage, authority, coverage of information, and authenticity. [19] developed a scale WEBQUAL to measure the service quality of websites. This scale was based on 12 service quality criteria. Later [20] proposed SITEQUAL - a scale to measure service quality in online context based on four dimensions: interactive responsiveness, speed of processing, ease of use, and aesthetic design. The criteria defined by [21] to evaluate websites consisted of performance, design, and usability matrices such as navigation, content, speed of download, responsiveness, and interactivity. [22] presented his own set of criteria to evaluate websites that consisted of trust, perceived ease of use and usefulness. [23] proposed website evaluation matrix consisting of five dimensions: reliability, interface, content, navigation, and technical. The limitation of these scales is that the focus of these scales mostly was to evaluate the websites and not the e-SQ.

[24] extended the scope of e-SQ beyond the web site interactivity by proposing eTailQ based on four quality dimensions: reliability/fulfillment, customer service, website design, and privacy/security. [14] proposed E-S-QUAL based on the following quality dimensions: privacy, efficiency, fulfillment, system availability. They proposed another scale E-RecS-QUAL consisting of three dimensions (responsiveness, compensation, and contact) to address the recovery component of e-service quality. The common feature of the scales mentioned here is that the evaluations mostly were based on customer perceptions - a subjective matter that lacks objectivity.

[25] defined a scale to objectively evaluate the e-SQ of ninety-eight websites across eight service sectors in Barbados. He used the Center for E-Commerce (CEC) website evaluation framework which consisted of six categories: ease of use, company information and function, buy/selltransactions, customer services, product/service information and promotion, and innovation in services \& technology. In each of these categories, five elements were defined. A total of thirty elements were used to evaluate a given website (six categories of five elements each). Each element was awarded a score of 1 or 0 depending on whether the given feature (or features) was present or not. A similar scoring mechanism is used in our proposed e-SQF.

[26] and [27] conceptualized the idea of e-SQ by exploring the process, outcome, and recovery dimensions of e-SQ. They recommended the following five dimensions to evaluate e-SQ process 
quality: ease of use, design, privacy, information, accuracy, and functionality. For evaluating eservice outcome quality three dimensions were suggested as order accuracy, order timeliness, and order condition. Finally, three dimensions for evaluating e-service recovery quality were proposed as interactive fairness, procedural fairness, and outcome fairness. [28] investigated e-SQ dimensions by reviewing SERVQUAL and other e-SQ scales and proposed 8-dimensions for measuring e-SQ: website design, responsiveness, security, reliability, fulfillment, information, personalization, and empathy. [29] defined the criteria for evaluation of e-services offered by B2C websites consisting of the following five dimensions: privacy, trust, personalization, payment security, and information and design. It can be concluded based on the foregoing that although different scales have been proposed to measure e-SQ, all of these scales lack specific application and validation [10]. There is a room to propose a scale that is comprehensive to assess the e-SQ of online retailers in the sense it cover all the phases of e-tailing starting from the product searching to sharing of post-sales experience.

\subsection{E-SQF and its Dimensions}

Systematic literature review was conducted to study the different models proposed by different researchers for measuring e-service quality. Based on the analysis of different e-service quality models (discussed in the previous section) it was realized that there is a room to propose a scale that is comprehensive to assess the e-SQ of online retailers in the sense it cover all the phases of e-tailing starting from the product searching to sharing of post-sales experience. The e-SQF proposed in this study is mainly based on the six dimensions of e-service quality proposed by [27]: e-search, e-response, e-transaction, e-payment, and assurance and trust. Although some of these dimensions are defined in other scales discussed in the literature review but no one scale has used all of them. Besides these six dimensions we have included two other dimensions in the e-SQF (post-sales support and website design $\&$ functionality) which are indicated as important e-service components by different researchers (e.g. see [24] and [27]). The details of these factors are presented next.

\subsubsection{E-Search}

The main objective of this e-service is to help visitors locate the product they need 24/7, conveniently and swiftly. Websites are using intelligent agents which are software designed to assist customers in locating the required goods or services using user-supplied keywords. Latest technologies being used for this service include data mining and data warehousing - these technologies are very useful for analyzing complex queries and identifying buying trends that enable e-tailers to send personalized offers to target consumers.

\subsubsection{E-Response}

Compared to responsiveness in SERVQUAL, responsiveness in e-SQ is a much narrower concept [28]; the reason being there is no face to face (or physical) interaction between the buyer and seller. The purpose of this service is to make online visitors comfortable and feel at home. By effectively using this service customer intimacy can be achieved. It is a useful tool to stay connected with customers by thanking them for their purchase of goods and services or apologizing them for any delays or sending personalized e-mails to assist them in selection of any product/service. The customers can be informed about any special promotions and/or launch of any new product/service. It is useful in getting attention of customers by promptly responding to their 
queries. Customers can be saved from anxiety by constantly keeping them informed of the status of their orders - confirmation of orders, delivery/shipment and payment information via e-mails or SMSs.

\subsubsection{E-Transaction}

It includes receiving orders online and payments. The orders are received using customized forms that indicate the item code, name, quality, price, and total cost of the order. The advantage is that there are less chances of error or incomplete information as compared to handwritten faxed orders. The customers can check the full details (review) of their order(s) before confirming. The e-tailing websites can offer multiple payment methods - suitable for different customers according to their needs - credit card, online transfers, cheque, or cash-on-delivery. Other payment methods besides credit cards are important in countries where credit card penetration is low, as is the case in Pakistan.

\subsubsection{E-Assurance \& Trust}

Whenever a technology is introduced one of the prime concern is the security and privacy [29], same is the case with e-commerce. E-tailers can assure customers about the security of transactions and communication by providing security information on their websites. Mostly the websites include a security icon or a link that contains information regarding website security.

\subsubsection{E- Help \& Technologies:}

The customers looking for online goods and services often require assistance in finding suitable product that meets their requirement. Also they want to verify the total cost of their order, delivery time, and mode of payment before finalizing their transaction. The common queries of customers are generally addressed in frequently asked questions (FAQs) section. The customers can be offered real life images of the product using 3-D technology. Sometimes online buyers are interested in knowing the feedback of other customers' who have already tried the goods and services of their interest. Online sellers can offer them an opportunity to connect to other customers via social networking sites such as Facebook, Google+, Twitter etc. An increasing number of customers are shopping online using their mobile devices and in order to facilitate them many online sellers have developed their mobile apps which assist customers during all the phases of an online transaction. Those who have not developed any mobile app ensure that their website is mobile compatible.

\subsubsection{Post-Sales Support}

Many e-tailers are offering online order tracking system which keeps customers informed about the whereabouts of their shipment. Generally, feedback on customers shopping experience is gathered and shared on the website. The customers are sometimes requested to rate the product on a certain rating scale (e.g., five-star rating scale) and then these ratings are posted on the website to assist potential customers in selecting a product or service.

\subsubsection{Website Design and Functionality}

Design is the visual appearance of the site [26]. A well-designed website can be very much helpful in attracting new customers and retaining the existing ones, while a poorly designed website can have a negative impact. The experts suggest that a website should be visually appealing, user friendly, and easy to navigate. The homepage should offer a complete map of the website and 
suitable icons that are easy to understand. The web pages should comfortably fit in browser window. The customers should be advised on ideal browser so that they could fully enjoy their visit. Functionality, according to [26], means that a website has quick page loads and ensures the absence of dead links. Sometimes a text only version (HTML) is offered to enable the customers having slow internet connection to view the contents fast. Another e-service is to offer printer friendly pages so that the customers who are interested in printing some information can easily do so. According to [28] website design should meet certain attributes for attracting customers and facilitating online purchases: well organized appearance, user interface, consistent and standardized navigation, and quick downloading.

\section{Methodology}

The proposed e-SQF consists of eight dimensions as discussed in the previous section. Items to measure these eight dimensions were adopted from the studies conducted on the topic of measuring the quality of e-commerce websites by [32], [23], and [25]). The face validity of the e-SQF was confirmed by different experts individually.

The e-SQF framework is applied on the ten most popular B2C e-commerce websites in Pakistan. Since no authentic list of most popular Pakistani websites exists, the following methodology was adopted: A search for the popular websites was conducted using the Google search engine on 26 February 2017 by using the following keywords "most popular e-commerce sites in Pakistan", "top e-commerce sites in Pakistan", "best e-commerce sites in Pakistan", "e-commerce awards Pakistan 2016". Based on the results of this search a list of commonly cited websites was prepared which was further refined to include only B2C websites offering multiple consumer products. The official Facebook pages of the shortlisted websites were visited to find out the number of likes in each case. Finally, the list was verified from the data published by Alexa's Traffic Ranking (www.alexa.com) and Similarweb (www.similarweb.com) The following ten vendors with the most likes were finally selected for further analysis: Daraz.pk, Yayvo.com, Symbios.pk, homeshopping.pk, iShopping,pk, techcity.pk, Kaymu, dealtoday.pk, shopdaily.pk and mega.pk.

The job of assessing the selected websites based on e-SQF was assigned to students enrolled in two different sections of e-commerce class during Spring 2017 semester. There were 32 students in each section who were further divided into 8 groups (consisting of four students each). All the ten websites were evaluated by each group, thus resulting in 16 reports altogether. The mean score for each website was calculated and final analysis was based on it. The maximum score any website could get was 92 (maximum 5 points for e-search, 5 points for e-response, 13 points for e-transaction, 6 points for e-payment, 7 points for e-assurance \& trust, 4 points for post-sales support). The scores on these seven dimensions were based on availability (in which case 1 is awarded) or non-availability (where 0 is awarded) of a specific feature. One dimension i.e., website design and functionality was evaluated little differently: six of the features covering this dimension were evaluated just like the other seven dimensions, however there were eight features that were evaluated on a scale of 1 to 5 due to which the maximum possible score in this case was 46 (see the attached appendix for complete details and scoring criteria). The results of the analysis are presented in the next section.

\section{Results and Discussions}


First of all, the selected $\mathrm{B} 2 \mathrm{C}$ websites were evaluated on the basis of each of the eight dimensions proposed in $\mathrm{e}-\mathrm{SQF}$ and the results are shown in figure 1:

Figure 1: Individual score for e-SQF proposed dimensions

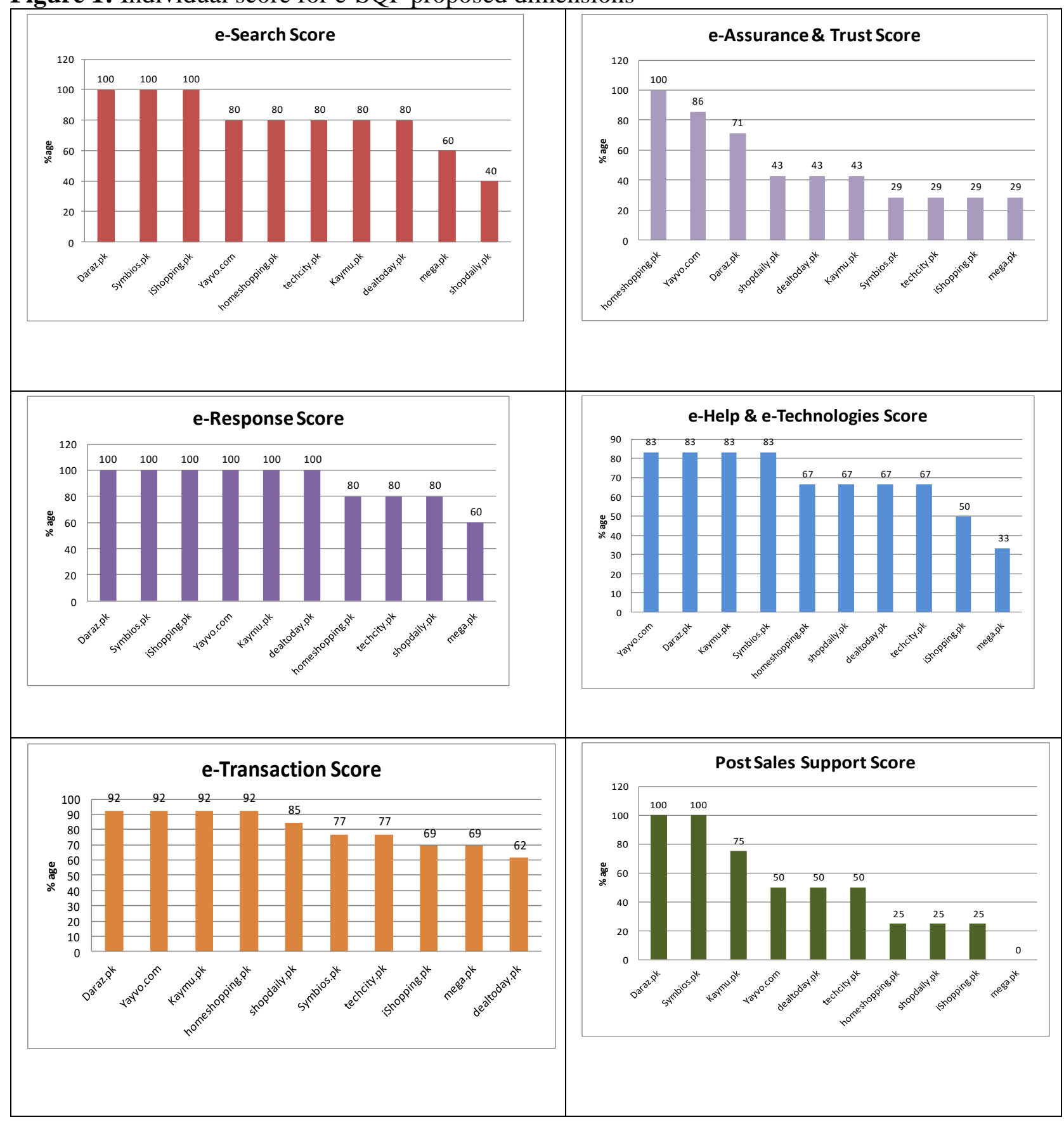




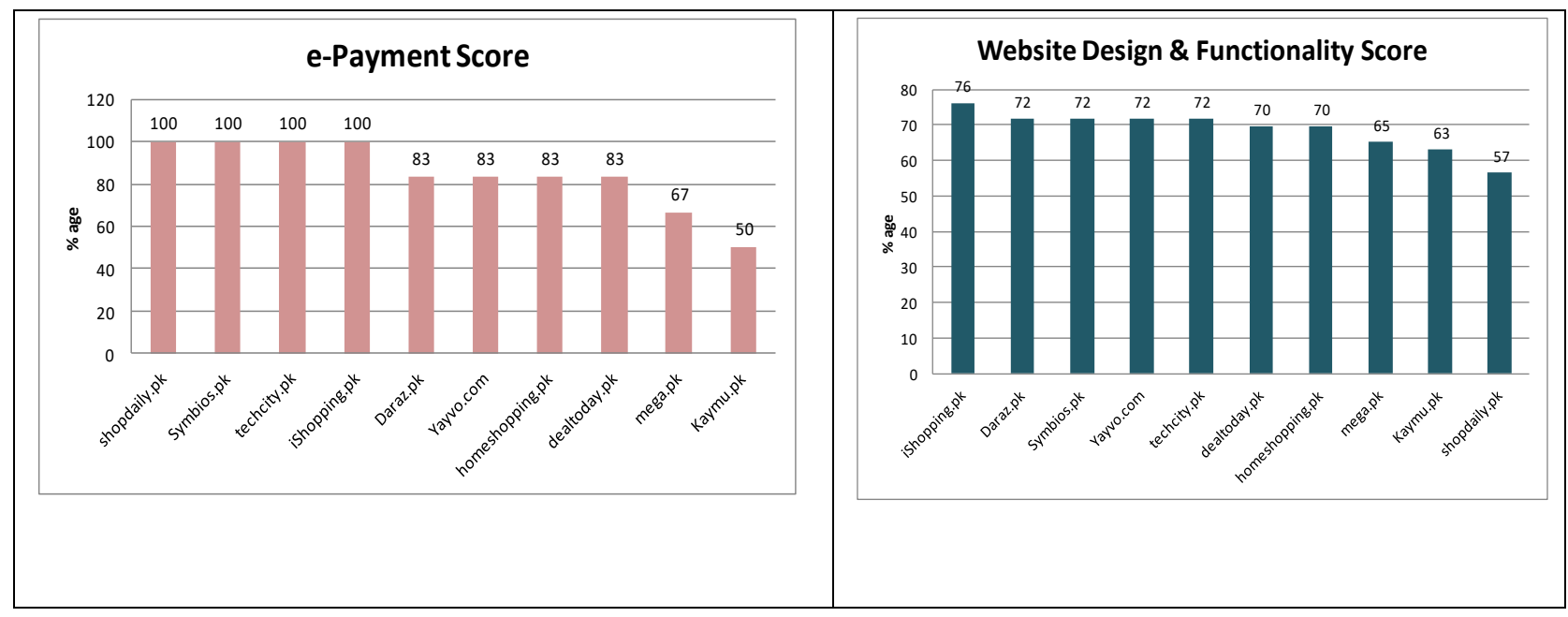

e-Search Scores: As shown in figure 1, three websites scored $100 \%$ while other five websites scored $80 \%$, Mega.pk scored $60 \%$ while shopdaily.pk scored the lowest $40 \%$ e-search score. The main factor contributing to low e-search score of few websites was the lack of a personalized recommendation system which is considered as one of the important features in online personalized services [33]. The other factor contributing to low e-search score was non-availability of advanced search option. Firms scoring high generally had a search option where customers could search by brand, product, cost, newness, popularity, and age etc.

e-Response Scores: Generally, the scores for e-response were above $80 \%$ ( 9 out of 10 firms scored $80 \%$ and above), which indicates that the companies are doing well in this particular area. There was only one website which did not offered online chat facility - a feature considered crucial for addressing customers' queries and concerns instantly.

e-Transaction Scores: Most of the websites in general have performed well in this dimension by scoring more than $70 \%$ points. The generic features such as shopping cart, customer personal account and confirmation before final check out are well understood and integrated in the websites. However, there were two areas where companies mostly lost their points: order cancellation and return policies. Order cancellation policy and/or sales return policy was not clearly defined in case of few of the websites. Another area to improve is saving order forms without creating an account. As a matter of fact, websites scoring low didn't have provision to save data form even if account is created. Failure to save order form means that the customer has to enter complete information every time he is going to order which is an unpleasant experience.

e-Payment Scores: Here four firms scored 100 while an equal number of websites scored 80 plus that suggests that it is a well focused area. Only two of the websites have lower scores which are due to non-availability of variety of cash payment methods. Kaymu.pk did not offered wired and online banking transaction which resulted in low score for the website in this dimension.

e-Assurance and trust Scores: E-Assurance and trust has emerged as one of the lowest scoring dimension for most of the websites. Six websites have scored less than 50 points and only two have scored more than 80. Mega.pk did not have information about security certificates and privacy guidelines. Except one website none of the rest had information about company's executives contact information.

e-Help \& e-Technologies Scores: Most of the firms have scored average. Mega.pk lagged behind in scores on this dimension primarily due to non-availability of mobile application, 3D pictures, and connecting to social media. 
Post-sales support Scores: This dimension has clearly played a vital role in segregating market leaders. Daraz.pk, symbios.pk and kaymu.pk are the only three scoring good, rest of the seven websites have failed to score above 50. Rather mega.pk has failed to score a single point for this dimension. Most of the websites have failed to score against solicited feedback and experience sharing with new customers.

Website Design and Functionality Scores: Measurement of few items in this dimension is subjective however the websites were evaluated on basic parameters and common benchmarks. The difference among websites is very narrow and marginal. None of the website guides user for ideal browser or provides text only version of web pages.

An overall assessment of each of the eight dimensions proposed in e-SQF was conducted next and the results are shown in figure 2:

Figure 2: Average Score for each of the eight dimensions of e-SQF

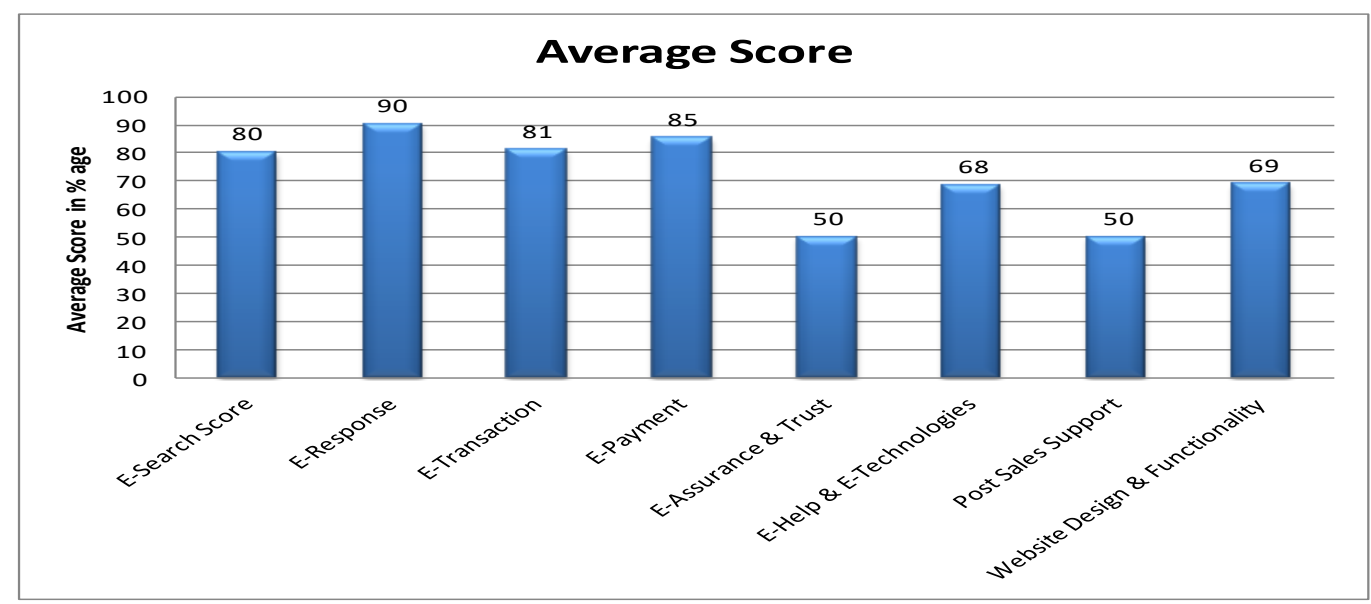

The above figure shows average scores of websites against each dimension and discloses the industry situation as per e-SQF. Four of the dimensions including e-response, e-payment, etransaction, and e-search have shown relatively good scores and average industry score is above 80. The selected websites have averagely scored against two of the dimensions namely website design \& functionality and e-help \& e-technologies. The areas to be improved here include offering a text only version and consideration for non-broadband users. Most of websites lacked recommendation for ideal browser and provision of printable version of product catalogue.

The most concerning issue (as reflected in figure 2) is seen in e-assurance $\&$ trust and post-sales support. In e-assurance \& trust websites lacked information of executives and security certificates. Having information about company executives always builds a trust; since people feel comfortable 
in reporting issues to top management in case it is not resolved at the lower level. In post-sales support websites generally need to work on soliciting customers' experiences and sharing the same in the shape of ratings. Another important feature lacking in case of some websites is the customer testimonials which are considered an important tool to encourage customers for online shopping.

The last part of the data analysis was to get cumulative scores for each of the selected websites and the results are presented in table 1:

\begin{tabular}{|c|c|c|c|c|c|c|c|c|c|c|c|}
\hline $\begin{array}{l}\text { Overall } \\
\text { Ranking }\end{array}$ & Website & $\begin{array}{c}\text { e-Search } \\
\text { Score }\end{array}$ & $\begin{array}{c}\text { e- } \\
\text { Response } \\
\text { Score }\end{array}$ & $\begin{array}{c}\text { e- } \\
\text { Transaction } \\
\text { Score }\end{array}$ & $\begin{array}{c}\text { e- } \\
\text { Payment } \\
\text { Score }\end{array}$ & \begin{tabular}{|c|} 
e- \\
Assurance \\
\& Trust \\
Score
\end{tabular} & $\begin{array}{l}\text { e-Help } \\
\text { \& e- } \\
\text { Technol } \\
\text { ogies } \\
\text { Score }\end{array}$ & $\begin{array}{c}\text { Post } \\
\text { Sales } \\
\text { Support } \\
\text { Score }\end{array}$ & \begin{tabular}{|c|} 
Website \\
Design \\
$\&$ \\
Function \\
ality \\
Score \\
\end{tabular} & $\begin{array}{l}\text { Total } \\
\text { Score }\end{array}$ & Percentile \\
\hline \multicolumn{2}{|c|}{ Max. Possible Score } & 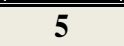 & 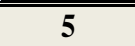 & 13 & $\overline{\overline{6}}$ & 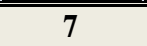 & ("6 & 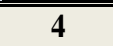 & "46 & 92 & $100 \%$ \\
\hline 1 & Daraz & 5 & 5 & 12 & 5 & 5 & 5 & 4 & 33 & 74 & 80 \\
\hline 2 & Yayvo.com & 4 & 5 & 12 & 5 & 6 & 5 & 2 & 33 & 72 & 78 \\
\hline 3 & Symbios & 5 & 5 & 10 & 6 & 2 & 5 & 4 & 33 & 70 & 76 \\
\hline 4 & homeshopping.pk & 4 & 4 & 12 & 5 & 7 & 4 & 1 & 32 & 69 & 75 \\
\hline 5 & iShopping.pk & 5 & 5 & 9 & 6 & 2 & 3 & 1 & 35 & 66 & 72 \\
\hline 6 & techcity.pk & 4 & 4 & 10 & 6 & 2 & 4 & 2 & 33 & 65 & 71 \\
\hline 7 & Kaymu & 4 & 5 & 12 & 3 & 3 & 5 & 3 & 29 & 64 & 70 \\
\hline 8 & dealtoday.pk & 4 & 5 & 8 & 5 & 3 & 4 & 2 & 32 & 63 & 68 \\
\hline 9 & shopdaily.pk & 2 & 4 & 11 & 6 & 3 & 4 & 1 & 26 & 57 & 62 \\
\hline 10 & mega.pk & 3 & 3 & 9 & 4 & 2 & 2 & 0 & 30 & 53 & 58 \\
\hline
\end{tabular}

Table 1: Cumulative e-SQ scores for the selected websites

The above table shows that Daraz.pk, which is considered as one of the most famous websites in Pakistan, scores maximum (74/92 or $80 \%)$ as per the criteria defined in e-SQF. The table shows that the difference of points is fairly distributed from the leader, daraz.pk, securing $80 \%$ as compared to the least scoring website, mega.pk with 53 points $(58 \%)$. It is important to note that these websites differ in their offerings, however the e-SQF used to rate these websites has generic checkpoints to assess their service quality. Therefore, the differences in the sales model of these websites might not have affected this evaluation. A comparative state of cumulative scores of each of the selected websites is shown in Figure 3:

Figure 3: Cumulative Average score for each Website 


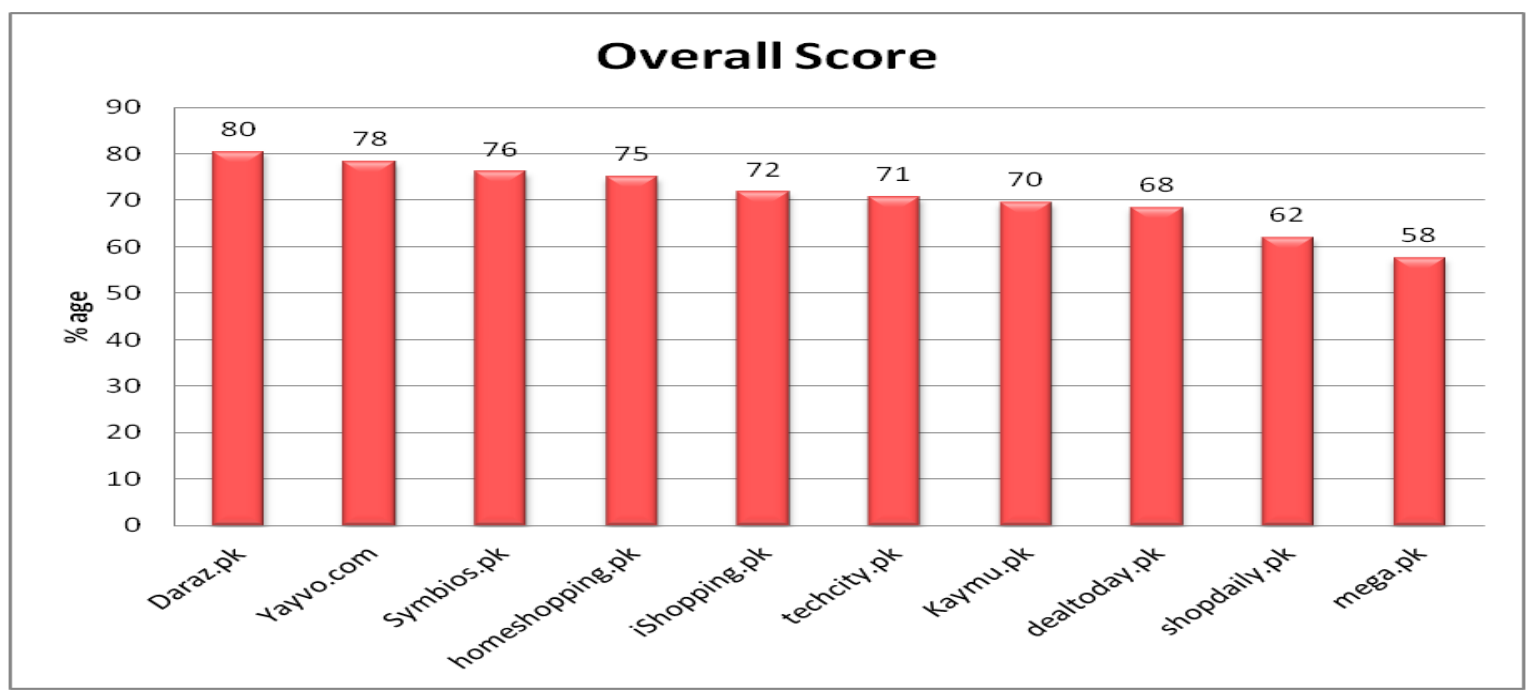

The results show good scores of the industry over four out of eight dimensions which are e-search, e-transaction, e-response and e-payment; whereas the scores for two dimensions i.e., e-help \& technology and website design \& functionality were average and the scores for remaining two dimensions i.e., e-assurance $\&$ trust and post sales support were relatively very low.

E-assurance \& trust is considered very important factors in shaping online purchase intention of the customers [34]. Websites analyzed in this study, in general, have scored very low on this dimension which could be a potential barrier in the growth of $\mathrm{B} 2 \mathrm{C}$ commerce in Pakistan. The etailers need to understand the importance of trust in online business model and as the customer don't have the privilege to assure the quality physically the businesses have to come up with ideas that can assure the quality without being touched and seen [35]. Properly addressing this dimension could improve online customers' trust and hence the overall sales of B2C websites. Furthermore [36] pointed out that the pre-purchase user perceptions of attributes and post-purchase user perceptions of attitudes are important concept in promoting successful online retail website; therefore, it is very important for websites to understand that post sales support is a crucial factor in influencing customers' buying behavior as well as achieving a competitive advantage.

\section{Conclusion}

The researchers have attempted to propose a scale that could objectively measure the e-service quality of e-retailers. The proposed scale consists of eight e-service quality dimensions seven of which are measured using a dichotomous scale, hence the results can be validated by simple observation of whether the website contain that feature or not. Only one dimension (i.e., website design) is measured using a five point Likert scale. In order to minimize the bias among the evaluators 16 different groups (consisting of four members each) were assigned the task of evaluating the selected websites. Each group consisted of pupils well versed with e-commerce and website designs. Moreover, most of them were frequently shopping online. An Average score for each item was calculated and final comparison was based on it.

Success or failure of B2C websites depends a lot on the quality of e-services offered as different researchers have pointed out e-SQ as the most important determinant of long-term performance 
and success for e-retailers ([12], [16], [24] and [37]). E-SQ covers all the aspects of facilitating a customer right from the first contact all the way to final purchase and ultimately re-purchase [10]. A website looking to win new customers should provide complete detail of its offerings and different ways through which a customer should be able to find his required product or service the e-search dimension of e-SQF focus on this feature of a website. A website can make a customer's visit memorable by acknowledging his visit and promptly addressing all his queries and concerns - a feature covered by e-response dimension of e-SQF. The online customers can be facilitated in placing their orders accurately and completely as well as their confidence level can be enhanced considerably by providing them full access to information related to company's policies related to cancellation of orders, claiming refunds, and returning the goods purchased - etransaction dimension of e-SQF address all these issues. The customers should be notified of the full amount (including taxes and other charges) payable and the full range of payment options available - covered in e-payment dimension of e-SQF. The customers should be fully assured about the privacy of their personal information as well as security of their financial information. Moreover, the details of company's executives as well as physical address of the company should be clearly stated on the website to gain customers' trust - covered by e-assurance and trust dimension of e-SQF. The websites should make full use of available e-technologies such as 3-D images, use of mobile apps, and access to social networking sites - all these features are covered in e-help and e-technologies dimension of e-SQF. Post-sales experience and feedback of the customer regarding products/services purchased should be solicited and shared on the website for the help and guidance of future customers - covered by post-sales support dimension of e-SQF. Finally, the website design should be visually appealing, innovative, and easy to use; taking the downloading speed into consideration - all these issues are addressed in website design and functionality dimension of e-SQF. Any website paying attention to all these dimensions can serve its customers better as well as gain a competitive advantage. The proposed e-SQF is an effective tool to quantity all these e-SQ features and can be useful in identifying the strong and weak areas of e-SQ.

\section{Theoretical \& Practical Implications}

The proposed e-SQF adds to the existing literature available on measuring e-SQ of B2C websites. Measuring the service quality of e-tailers is an area of research that is unique in the sense its dynamics are changing every passing day. The scale defined in this study is comprehensive to assess the e-SQ of online retailers in the sense it covers all the phases of e-tailing starting from the product searching to sharing of post sales experience. The scoring mechanism defined is simple to apply and unbiased, since it grants points mostly on the basis of availability and non-availability of a specific feature. Moreover, it could effectively be used in identifying the strengths and weaknesses in e-SQ of a particular B2C website as well as comparing different websites to find out their relative strengths and weaknesses. The framework proposed in this study can be applied to any e-tailing website to calculate its overall e-SQ score as well to find out the relative strong and weak areas of e-services offered. Hence, it can be helpful in improving the overall e-SQ of etailers.

\section{Limitations \& Directions for Future Research}


The following are some of the limitations of this study: Firstly, we could not find an authentic list of top ten e-commerce websites of Pakistan, therefore we selected ten most popular websites on the basis of Facebook likes; however, we acknowledge most popular does not necessarily means the best. Secondly, the websites of companies are continuously updated; hence an evaluation of the same websites at another point in time might yield different results. Thirdly, although the researchers attempted to come up with a scale that give reliable results irrespective of evaluators bias, yet some of the items related to website design and functionality could still yield different scores based on the evaluators' personal likes and dislikes. Since the e-technologies are continuously improving every day, the proposed scale is open to further expansion and improvement.

\section{References}

[1] Oliveira, T., Alhinho, M., Rita, P., \& Dhillon, G. (2017). Modelling and testing consumer trust dimensions in e-commerce. Computers in Human Behavior, 71, 153-164.

[2] Molla, A., \& Licker, P. S. (2001). E-commerce systems success: An attempt to extend and respecify the Delone and MacLean model of IS success. J. Electron. Commerce Res., 2(4), 131-141.

[3] Chaffey, D. (2015). Digital business and E-commerce management. 6th edition. Pearson Education Limited.

[4] Global B2C E-Commerce Report (2016). [Online]. Available: https://www.google.com/url?sa=t\&rct=j\&q=\&esrc=s\&source=web\&cd=1\&cad=rja\&uact =8\&ved=0ahUKEwir9O X06jUAhXBXBoKHfKkCgkQFgg5MAA\&url=https\%3A\%2F \%2Fwww.ecommercewiki.org\%2Fwikis\%2Fwww.ecommercewiki.org\%2Fimages\%2F5 \%2F56\%2FGlobal_B2C_Ecommerce_Report_2016.pdf\&usg=AFQjCNFpyrI4OjyTZwHWs0irBxqOg74pw\&sig2=Bnd-wjSCd6BA7f4JlrYXUA

[5] PR Newswire (2016). 2016 a Landmark for Online Shopping in Pakistan Says PakStyle.pk. [Online].Available:http://www.prnewswire.com/news-releases/2016-a-landmark-foronline-shopping-in-pakistan-says-pakstylepk-300232847.html

[6] Tribune (2016). Pakistani e-commerce expected to hit by US\$ 1billion by 2020. [Online]. Available: $\quad$ https://tribune.com.pk/story/1259902/fast-growing-sector-pakistani-ecommerce-expected-hit-1b-2020-khurram/

[7] Iqbal, S., ur Rehman, K., \& Hunjra, A. I. (2012). Consumer intention to shop online: B2C E-commerce in developing countries. Middle East Journal of Scientific Research, 12(4).

[8] UNCTAD (2016). UNCTAD B2C E-COMMERCE INDEX 2016. [Online]. Available: http://unctad.org/en/PublicationsLibrary/tn_unctad_ict4d07_en.pdf 
[9] Hsu, S. H. (2008). Developing an index for online customer satisfaction: Adaptation of American Customer Satisfaction Index. Expert systems with Applications, 34(4), 30333042.

[10] Ladhari, R. (2010). Developing e-service quality scales: A literature review. Journal of Retailing and Consumer Services, 17(6), 464-477.

[11] Fassnacht, M., \& Köse, I. (2007). Consequences of web-based service quality: uncovering a multi-faceted chain of effects. Journal of Interactive Marketing, 21(3), 35-54.

[12] Santos, J. (2003). E-service quality: a model of virtual service quality dimensions. Managing Service Quality: An International Journal, 13(3), 233-246.

[13] Cristobal, E., Flavián, C., \& Guinaliu, M. (2007). Perceived e-service quality (PeSQ) Measurement validation and effects on consumer satisfaction and web site loyalty. Managing service quality: An international journal, 17(3), 317-340.

[14] Parasuraman, A., Zeithaml, V.A., Malhotra, A. (2005). E-S-Qual: a multiple-item scale for assessing electronic service quality. Journal of Service Research 7 (3), 213-233.

[15] Parasuraman, A., Zeithaml, V. A., \& Berry, L. L. (1988). Servqual: A multiple-item scale for measuring consumer perceptions. Journal of retailing, 64(1), 12.

[16] Fassnacht, M., \& Koese, I. (2006). Quality of electronic services: Conceptualizing and testing a hierarchical model. Journal of service research, 9(1), 19-37.

[17] Aladwani, A. M., \& Palvia, P. C. (2002). Developing and validating an instrument for measuring user-perceived web quality. Information \& management, 39(6), 467-476.

[18] Kapoun, J. (1998). Teaching undergrads WEB evaluation: A guide for library instruction. College \& Research Libraries News, 59(7), 522-523.

[19] Loiacono, E. T., Watson, R. T., \& Goodhue, D. L. (2002). WebQual: A measure of website quality. Marketing theory and applications, 13(3), 432-438.

[20] Yoo, B., \& Donthu, N. (2001). Developing a scale to measure the perceived quality of an Internet shopping site (SITEQUAL). Quarterly journal of electronic commerce, 2(1), 3145 .

[21] Palmer, J. W. (2002). Web site usability, design, and performance metrics. Information systems research, 13(2), 151-167.

[22] Schubert, P. (2002). Extended web assessment method (EWAM): evaluation of electronic commerce applications from the customer's viewpoint. International Journal of Electronic Commerce, 7(2), 51-80. 
[23] Van der Merwe, R., \& Bekker, J. (2003). A framework and methodology for evaluating ecommerce web sites. Internet Research, 13(5), 330-341.

[24] Wolfinbarger, M., \& Gilly, M. C. (2003). eTailQ: dimensionalizing, measuring and predicting etail quality. Journal of retailing, 79(3), 183-198.

[25] Walcott, P. (2007). Evaluating the readiness of e-commerce websites. International Journal of Computers, 1(4), 263-268.

[26] Collier, J. E., \& Bienstock, C. C. (2003). E-service quality: understanding the dimensions of quality for online shopping experiences. Developments in Marketing Science, 26, 15862.

[27] Collier, J. E., \& Bienstock, C. C. (2006). Measuring service quality in e-retailing. Journal of service research, 8(3), 260-275.

[28] Li, H., \& Suomi, R. (2009). A proposed scale for measuring e-service quality. International Journal of u-and e-Service, Science and Technology, 2(1), 1-10.

[29] Basahel, A., \& Yamin, M. (2017). Measuring success of e-government of Saudi Arabia. International Journal of Information Technology, 9(3), 287-293.

[30] Castro, A., Puente, J., Gómez, A., Fernández, I., \& Ponte, B. (2013, January). The quality of e-service in b2c websites: an approximation with fuzzy decision support systems. In Proceedings on the International Conference on Artificial Intelligence (ICAI) (p. 1). The Steering Committee of The World Congress in Computer Science, Computer Engineering and Applied Computing (WorldComp).

[31] Singh, M. (2002). E-services and their role in B2C e-commerce. Managing Service Quality: An International Journal, 12(6), 434-446.

[32] Olsina, L., Lafuente, G., \& Rossi, G. (2000, September). E-commerce site evaluation: A case study. In International Conference on Electronic Commerce and Web Technologies (pp. 239-252). Springer Berlin Heidelberg.

[33] Wei, K., Huang, J., \& Fu, S. (2007, June). A survey of e-commerce recommender systems. In Service systems and service management, 2007 international conference on (pp. 1-5). IEEE.

[34] Huang, S. L., \& Chang, Y. C. (2017, January). Factors that impact consumers' intention to shop on foreign online stores. In Proceedings of the 50th Hawaii International Conference on System Sciences.

[35] Zeng, W., \& Richardson, A. (2016). The Role of Translated Information Quality in a Global e-Retailing Context. arXiv preprint arXiv:1606.00891. 
[36] Rezaei, S., Chandran, R., \& Oh, Y. M. (2017). Pre-Purchase User Perceptions of Attributes and Post-Purchase Attitudes in Building Successful Online Retail Promotional Strategies. In Promotional Strategies and New Service Opportunities in Emerging Economies (pp. 164-183). IGI Global.

[37] Holloway, B. B., \& Beatty, S. E. (2003). Service failure in online retailing: A recovery opportunity. Journal of service research, 6(1), 92-105. 
Appendix: $\underline{\mathrm{e}-\mathrm{SQF}}$

E-COMMERCE SERVICE QUALITY (ESQ) FRAMEWORK

\begin{tabular}{|c|c|c|c|c|}
\hline E-Sevice Dimension & & & No (0) & Yes (1) \\
\hline \multirow{5}{*}{ 1. E-Search } & 1 & Website contains comprehensive product catalogue & & \\
\hline & 2 & $\begin{array}{l}\text { Website offers multiple search options (Quick search/Advanced } \\
\text { Search) }\end{array}$ & & \\
\hline & 3 & $\begin{array}{l}\text { Website offers customized recommendations for any items } \\
\text { searched }\end{array}$ & & \\
\hline & 4 & E-subscription option is available & & \\
\hline & 5 & What's new feature is available & & \\
\hline \multicolumn{5}{|c|}{ Total Score (Minimum Score = 0; Maximum Score $=5$ ) } \\
\hline \multirow[t]{5}{*}{ 2. E-Response } & 6 & Website offers customized e-mails & & \\
\hline & 7 & Order acknowledgement emails are sent to customers & & \\
\hline & 8 & Customer querries are addressed quickly & & \\
\hline & 9 & Online chat facility is available & & \\
\hline & 10 & Thankyou emails are sent to customers for enquiries or orders & & \\
\hline \multicolumn{5}{|c|}{ Total Score (Minimum Score = 0; Maximum Score $=5$ ) } \\
\hline \multirow[t]{13}{*}{ 3. E-Transaction } & 11 & The website offers standard order forms & & \\
\hline & 12 & $\begin{array}{l}\text { Customers are able to save order form to retrieve at a later time or } \\
\text { date }\end{array}$ & & \\
\hline & 13 & Customers can check order and total costs before confirmation & & \\
\hline & 14 & Shopping cart faciilty is available & & \\
\hline & 15 & Items available in stock are shown & & \\
\hline & 16 & $\begin{array}{l}\text { Prices (inclusive of tax or otherwise) are shown with each item } \\
\text { offered by the site }\end{array}$ & & \\
\hline & 17 & Edit/recalculate feature is available for ordered items & & \\
\hline & 18 & Purchase cancellation policy is clearly stated & & \\
\hline & 19 & Goods return policy is clearly stated on the website & & \\
\hline & 20 & $\begin{array}{l}\text { Shipping and Handling Information is available for the goods } \\
\text { ordered }\end{array}$ & & \\
\hline & 21 & Confirmation of order dispatch is sent to the customer & & \\
\hline & 22 & $\begin{array}{l}\text { Multiple delivery time options (next day, } 3 \text { to } 5 \text { day, } 5 \text { to } 7 \text { days) } \\
\text { are available }\end{array}$ & & \\
\hline & 23 & The customers can access the record of their past transactions & & \\
\hline \multicolumn{5}{|c|}{ Total Score (Minimum Score = 0; Maximum Score $=13$ ) } \\
\hline \multirow[t]{6}{*}{ 4. E-Payment } & 24 & The website offers cash on delivery option & & \\
\hline & 25 & Paymenst can be made using credit cards (Visa/MasterCard) & & \\
\hline & 26 & Payments can be made via Cheques/Bank/Wire transfer & & \\
\hline & 27 & Mobile payments (Easy paisa/Mobicash) are accepted & & \\
\hline & 28 & Payment confirmation email/SMS is sent to customers & & \\
\hline & 29 & $\begin{array}{l}\text { Customers are notified total ordering cost (including shipping cost } \\
\text { and tax)before payment processing }\end{array}$ & & \\
\hline \multicolumn{5}{|c|}{ Total Score (Minimum Score = 0; Maximum Score $=6$ ) } \\
\hline \multirow[t]{7}{*}{ 5. E-Assurance \& Trust } & 30 & Security Information is well communicated to customers & & \\
\hline & 31 & Customers are assured about privacy of their personal information & & \\
\hline & 32 & Security certificates are adequate & & \\
\hline & 33 & Secured transaction icon/symbol/message is visible & & \\
\hline & 34 & Company's postal and physical address is available & & \\
\hline & 35 & Company executives information/contacts are available & & \\
\hline & 36 & Telephone and fax numbers are available & & \\
\hline \multicolumn{5}{|c|}{ Total Score (Minimum Score = 0; Maximum Score = 7) } \\
\hline \multirow{6}{*}{$\begin{array}{l}\text { 6. E-Help \& E- } \\
\text { Technologies }\end{array}$} & 37 & FAQs are available & & \\
\hline & 38 & 3D Photographs/Thumbnails for products sold are offered & & \\
\hline & 39 & Zooming of products offered for sale is available & & \\
\hline & 40 & \multicolumn{3}{|c|}{ Website is customized to be accessed from mobile devices (e.g., Android, iOS etc.) } \\
\hline & 41 & Website has a local application to be used on the mobile device & & \\
\hline & 42 & \multicolumn{3}{|c|}{ Website offers connections to social networking sites such as facebook, twitter, G+ } \\
\hline \multicolumn{5}{|c|}{ Total Score (Minimum Score = 0; Maximum Score $=6$ ) } \\
\hline \multirow[t]{4}{*}{ 7. Post Sales Support } & 43 & Customer feedback is collected on their shopping experience & & \\
\hline & 44 & Customer ratings are solicited and displayed on the website & & \\
\hline & 45 & $\begin{array}{l}\text { Customer testimonials of shopping experience are } \\
\text { recorded/shared }\end{array}$ & & \\
\hline & 46 & Online order tracking facility is available & & \\
\hline & & al Score (Minimum Score = 0; Maximum Score =4) & & \\
\hline
\end{tabular}




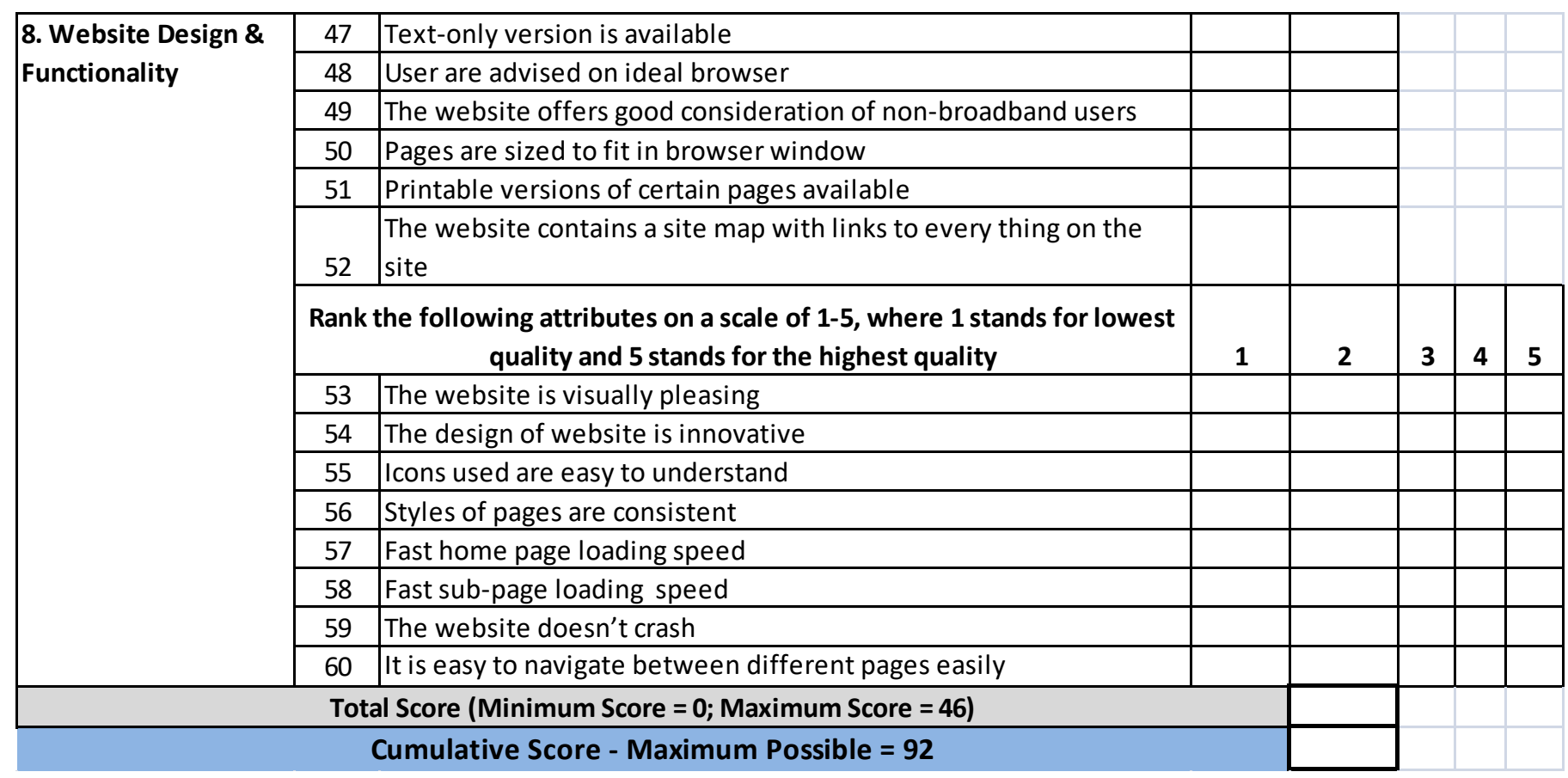

